\title{
CIHR cutting MD/PhD training program
}

$\mathrm{R}$ epudiating advice from two expert advisory panels, the Canadian Institutes of Health Research (CIHR) is ending its MD/ PhD Program, which, for more than three decades, has helped hundreds of Canadian medical students train to become clinician-scientists.

In a June 18 letter sent to directors of the $\mathrm{MD} / \mathrm{PhD}$ program at medical schools across Canada, CIHR's Director of Science, Knowledge Translation and Ethics Danika Goosney announced the 2015/16 academic year will be the program's last. While noting that efforts are underway within CIHR to overhaul its entire approach to scientific training, Goosney cited "recent pressures on CIHR's budget" as the leading reason for the termination. CIHR's billion dollar annual federal appropriation has not been increased since 2009, meaning that its spending power has declined by roughly $25 \%$ since then.

The $\mathrm{MD} / \mathrm{PhD}$ program has an annual budget of about $\$ 1.8$ million. It typically provides multiyear grants of about $\$ 22000$ to some 20 incoming students annually for varying multiyear periods often spanning more than five years. At any given time it helped support over 100 clinician-scientists in training.

Goosney said CIHR is developing a strategic action plan for health-research trainees, and will continue to fund other doctoral and postdoctoral scholarship programs, some of which are available to medical students, though for shorter periods than the MD/PhD program. "We do have other programs available and we are developing a training strategy. The wheels are in motion."

The existing programs cited by Goosney include the three-year Vanier Canada Graduate Scholarships for incoming $\mathrm{PhD}$ students, the three-year CIHR Doctoral Research Awards, the two-year Banting Postdoctoral Fellowships, and the three- to five-year CIHR fellowships for those holding or completing a $\mathrm{PhD}$ or health professional degree.

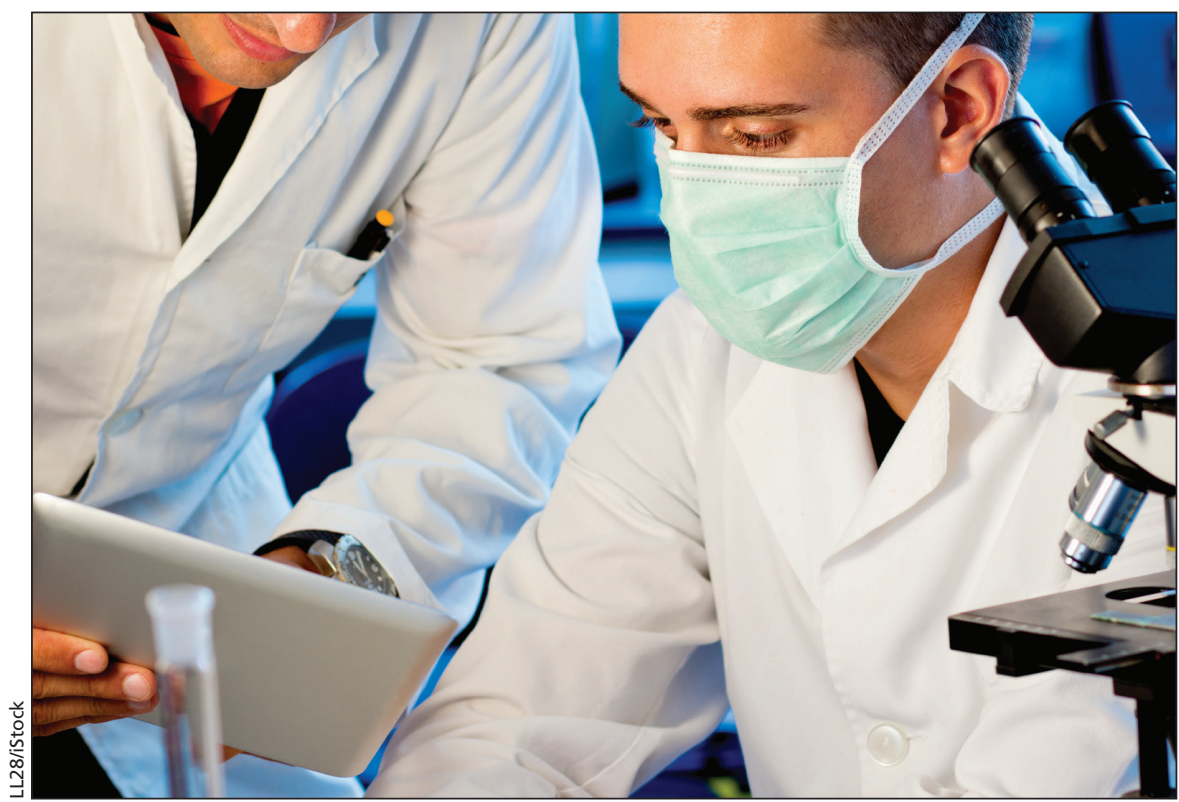

CIHR's 30-year-old clinician-scientist training program will end in 2016.

In scrapping the $\mathrm{MD} / \mathrm{PhD}$ program without first elaborating on a plan to replace or reform it, the CIHR has made a "disturbing" decision that flies in the face of strong advice from the 11-member Advisory Committee on Training and Career Development convened by CIHR, said Dr. Norman Rosenblum, who chaired the committee.

Rosenblum, associate dean of Physician Scientist Training at the University of Toronto, said his committee's 75-page report to the CIHR's National Steering Committee of the Strategy for Patient-Oriented Research in 2013, explicitly advised CIHR to "increase equitable access to the $\mathrm{MD} / \mathrm{PhD}$ grant program." Ideally, the report added, "expanded recipients would be supported by expanded resources," and "significant effort should be undertaken to find new partners which could help support an expanded $\mathrm{MD} / \mathrm{PhD}$ program."

"It's disturbing CIHR cancelled it without any semblance of us understanding whether there is a transition plan to ensure continuity in meeting this need," Rosenblum said.

This is the second time external advisors recommended that CIHR bol- ster its support for clinician-researchers. In 2011, a committee of experts expressed "particular concern about the support for clinician-scientists" and recommended that "CIHR should work with the nation's universities to enhance the career paths of its young investigators. Particular attention should be paid to clinical investigators who must balance clinical service obligations with research."

In scrapping the program before putting new alternatives in place, Rosenblum said, "there has been no engagement or consultation about this decision. Absolutely nothing." Dr. Lynn Raymond, director of the MD/PhD program at the University of British Columbia (UBC) in Vancouver, and Dr. Mark Eisenberg, who directs the program at McGill University in Montréal, concur: "I was on the floor with shock," Raymond said. "This is insane," said Eisenberg.

The CIHR's decision is particularly perplexing in light of the agency's failure to conduct an assessment of the $\mathrm{MD} / \mathrm{PhD}$ program's utility and impact, said Rosenblum. "CIHR has no evaluation data on its training programs," he said, while not- 
ing that a June 2014 report from the US National Institutes of Health (NIH) Physician-Scientist Workforce Working Group recommended NIH "sustain strong support for the training of $\mathrm{MD} / \mathrm{PhDs}$."

That recommendation was based on evidence that $\mathrm{MD} / \mathrm{PhDs}$ have higher award rates for research grants than researchers without both degrees, Rosenblum said. "NIH's investment in the training of physician-scientists has a significant return," the working group report concluded.
Several clinician-researchers who trained with support from the CIHR's $\mathrm{MD} / \mathrm{PhD}$ program emphatically reject CIHR's claim that equivalent alternatives to the program remain available to trainees.

"The MD/PhD program is seven to eight years," concurs Dr. Liam Brunham, a principal investigator at UBC's Centre for Heart Lung Innovation. "I am not aware of other funding mechanisms that would support students over this period of time."
Dr. Suneil Kalia, a scientist at the Toronto Western Research Institute, predicted that "the ripple effects will be great" unless CIHR rapidly redresses its decision. "I strongly disagree with the statement that alternatives to this program already exist. They need to put a new pathway in place for these trainees before terminating the current program, not after the fact." — Paul Christopher Webster, Toronto

CMAJ 2015. DOI:10.1503/cmaj.109-5124 